\title{
Is the Secure Base Phenomenon Evident Here, There, and Anywhere? A Cross-Cultural Study of Child Behavior and Experts' Definitions
}

\author{
German Posada, Ting Lu, Jill Trumbell, \\ and Garene Kaloustian \\ Purdue University \\ Sandra J. Plata, Paola P. Peña, \\ and Jennifer Perez \\ Universidad Javeriana
}
Gabrielle Coppola, Alessandro Constantini, and Rosalinda Cassibba
University G. D'Annunzio, Chieti-Pescara \& University A. Moro, Bari

\author{
Marcel Trudel \\ University of Sherbrooke
}

\author{
Susana Tereno and Romain Dugravier \\ Université Paris Descartes E University Denis Diderot, \\ Paris VII
}

Kiyomi Kondo-Ikemura

University of Sapporo

\author{
Keng-Ling Lay \\ National Taiwan University
}

\begin{abstract}
The evolutionary rationale offered by Bowlby implies that secure base relationships are common in child-caregiver dyads and thus, child secure behavior observable across diverse social contexts and cultures. This study offers a test of the universality hypothesis. Trained observers in nine countries used the Attachment Q-set to describe the organization of children's behavior in naturalistic settings. Children $(N=547)$ were $10-72$ months old. Child development experts $(N=81)$ from all countries provided definitions of optimal child secure base use. Findings indicate that children from all countries use their mother as a secure base. Children's organization of secure base behavior was modestly related to each other both within and across countries. Experts' descriptions of the optimally attached child were highly similar across cultures.
\end{abstract}

The secure base phenomenon is at the core of Bowlby and Ainsworth's analysis of the infant-mother rela-

This research was supported in part by a grant from the National Science Foundation, NSF-0645530. This project was made possible thanks to the collaboration of all authors who gathered the information presented in their different countries. Countries are listed alphabetically: Canada: Marcel Trudel; Colombia: Sandra J. Plata, Paola P. Peña, and Jennifer Perez; France: Susana Tereno and Romain Dugravier; Italy: Gabrielle Coppola, Alessandro Constantini, and Rosalinda Cassibba; Japan: Kiyomi Kondo-Ikemura; Peru: Magaly Noblega, Ines M. Haya, and Claudia Pedraglio; Portugal: Manuela Verissimo, Antonio J. Santos, and Ligia Monteiro; Taiwan: Keng-Ling Lay; and the United States: German Posada, Ting Lu, Jill Trumbell, and Garene Kaloustian.

Correspondence concerning this article should be addressed to German Posada, HDFS Department, Purdue University, West Lafayette, IN 47907. Electronic mail may be sent to gposada@ purdue.edu. tionship. Ainsworth coined the term "secure base behavior" based on her naturalistic observations of infant-mother interactions in rural Uganda. When reviewing her field notes, she noticed that infants "do not always stay close to the mothers but rather make little excursions away from her, exploring other objects and interacting with other people, but returning to the mother from time to time" (Ainsworth, 1967, p. 345). The hallmark of secure base behavior is the seemingly purposeful balance between excursions or explorations away from the

(C) 2013 The Authors

Child Development (c) 2013 Society for Research in Child Development, Inc. All rights reserved. 0009-3920/2013/xxxx-xxxx

DOI: $10.1111 /$ cdev. 12084 
caregiver and proximity seeking at different times and across contexts. This phenomenon is hypothesized to be observable in children who have been exposed to ordinary parental care. A child will use her or his main caregiver(s) as a secure base from which to explore and learn about her or his surroundings, and to which to come back, if an emergency situation arises, or if the child is fatigued or ill (Bowlby, 1988).

\section{The Universality of the Secure Base Phenomenon}

In conceptualizing his model of instinct to explain the motivational basis of attachment behavior, Bowlby (1969/1982) abandoned Freud's notion of drives and proposed a model that integrated elements from control systems and ethological theories. He suggested that attachment behaviors (e.g., crying, sucking, smiling, clinging, and following), once isolated, become organized into a behavioral system during the 1st year. In the course of daily infant-mother interactions, attachment behaviors are put together into a behavioral control system with the goal of physical proximity to the caregiver (s). The system coordinates and integrates information about the child, caregiver, and surrounding context to initiate or terminate attachment behavior. To account for the existence of such a behavioral control system, Bowlby provided an evolutionary rationale and argued that a propensity to organize an attachment behavioral system has been selected due to survival advantages it afforded to those individuals that, in the course of human evolution, searched for proximity to main caregivers. That is, selection pressures favored the inclusion of such a propensity to form secure base relationships with caregiving figures. This feature of our behavioral equipment is not exclusive to humans, but indeed shared with other primates (Bowlby, 1969/1982).

One testable implication of Bowlby's rationale concerns the existence of the secure base phenomenon in children across social contexts and cultures. Research on infants and children's secure base behavior, as assessed in the Strange Situation and in naturalistic contexts in both Western industrialized cultures (De Wolff \& van IJzendoorn, 1997; Goldsmith \& Alansky, 1987) and those other than AngloSaxon and European (van IJzendoorn \& Sagi, 2008; see also Posada, Carbonell, Alzate, \& Plata, 2004; Vereijken, Riksen-Walraven, \& Kondo-Ikemura, 1997; Wu \& Zou, 1995) offers evidence in support of the notion that the secure base phenomenon can be observed and described in different cultural, social contexts, and situations.
In the only study explicitly testing the crosscultural universality hypothesis, Posada et al. (1995) asked mothers to report on their child's behavior using the Attachment Q-set (AQS; Waters, 1995). Information gathered was used to test whether secure base behavior was observable at home during child-mother interactions in children from seven different countries and socioeconomic backgrounds whose average age ranged between 1 and 3.5 years. Results indicated that infants and children's behavior in samples from China, Colombia, Germany, Israel, Japan, Norway, and United States was organized in ways similar to the secure base phenomenon. The study, however, had some limitations and unanswered questions, namely: the lack of trained observers providing data on child behavior (Heinicke, 1995; see van IJzendoorn, Vereijken, Bakermans-Kranenburg, \& Riksen-Walraven, 2004, for the importance of using trained observers), the need to expand the findings to new countries and replicate them with different samples from countries where the phenomenon was studied (Bretherton, 1995), and the need to test the results with samples of preschoolers.

To offer a new test of the universality hypothesis, and to address the limitations mentioned, we put together a collaborative observational study of child-mother interactions in naturalistic settings to investigate whether children's behavior is organized in ways that indicate use of the mother as a secure base. Research labs from nine different countries, Canada, Colombia, France, Italy, Japan, Peru, Portugal, Taiwan, and the United States, participated in this project. These countries certainly represent different cultures and contexts for development (see Oyserman, Coon, \& Kemmelmeier, 2002).

Understanding secure base behavior in diverse cultures also requires information on how child development experts within particular cultures view the phenomenon. Typically, experts' conceptualizations and definitions are used to assess infants and children's organization of secure base behavior. It is important to determine whether these conceptualizations differ and, if they do, whether such differences are culturally specific. Thus, we also collected experts' definitions about the optimal organization of secure base behavior in each of the participating countries.

All research groups used the AQS to describe children's secure base behavior and experts' definitions. The AQS is considered one of the gold standards when assessing attachment behavior (van IJzendoorn et al., 2004). It has the advantage of 
characterizing all children in terms of a common, well-defined language provided by the q-items. The items are placed and rated according to a standard distribution, thus facilitating comparisons among groups and individuals (Block, 1978). Key characteristics of the AQS for this project are as follows: (a) It does not presume the existence of the secure base phenomenon; the presence or absence of secure base behavior is inferred from descriptions of the child as per the Q-set. (b) It keeps observers blind to the construct being assessed and lends itself to an array of quantitative analyses. (c) Finally, it provides an economical, observational alternative that allows for the study of larger samples in naturalistic settings.

We investigated two questions regarding child behavior. First, we explored whether trained observers' descriptions of behavior (as per the AQS) during children's interactions with their mothers in naturalistic settings reflect the secure base phenomenon in the samples studied. If this were so, results would provide support for the universality hypothesis. We expected that most children's AQS security scores would be positive; that is, most children would use the mother as a secure base. Second, even if secure base behavior were present in all samples, it is important to investigate whether specific behavioral patterns (children's AQS descriptions) are similar across countries, or whether they are more similar within countries. Similarity of behavioral organization across (vs. within) countries would support the universality hypothesis (vs. the notion that specific social or cultural factors determine secure base use). On the basis of existing evidence (Posada et al., 1995; van IJzendoorn \& Kroonenberg, 1988), we expected security scores within and across countries to be similar; that is, patterns of secure base behavior were hypothesized to be comparable across samples.

As definitions of optimality are concerned, we asked whether optimal secure base behavior is defined similarly across countries, or whether the definition varies depending on culture. Based on existing evidence (Posada et al., 1995), it was hypothesized that experts' definitions of optimal secure base behavior are very similar across countries. Thus, it was expected that experts' definitions by country would be highly and significantly correlated across samples.

\section{Method}

\section{Participants}

A total of 547 children across nine participating countries were observed at their homes. Colombian,
Peruvian, and U.S. children were additionally observed at a playground. AQS descriptions of their behavior were obtained. Between 6 and 15 child experts per country $(N=81)$ provided descriptions of optimal child behavior during interactions with mother using the AQS. Table 1 presents a summary of sample demographic information by country.

Overall, children were between 10 and 72 months of age; mean age by country ranged from 14 to 61 months. All children were healthy and came from nonclinical populations; the French sample, however, came from a high risk, lowsocioeconomic-status (SES) population. There were approximately equal numbers of boys (278) and girls (269). Mothers were the main caregiver for all children and their mean age by country ranged from 24 to 35 years. Mothers' mean years of education by country ranged from 10 to 16.5 years. The range of the mean number of children per family by country was 1 to 2 . All child-mother dyads came from intact families except for 2 dyads in Taiwan and 12 single mothers in the French sample.

Most child experts who provided descriptions of optimal child behavior were psychologists. In Canada, 2 of 8 were professionals in psycho-education, and in Taiwan 4 of 10 were experts in early childhood education. Experts' areas of specialization were not necessarily that of child-mother relationships, except for those in the United States; however, all had at least some familiarity with attachment theory. Approximately 80\% (65) were female experts, and their mean level of education ranged from 17 to 22.9 years.

\section{Procedures}

Information about child secure base behavior was collected in different sociocultural contexts by independent labs that were conducting independent research projects with different goals. Child-mother dyads were observed by the authors and their trained research assistants or students. The study was explained in detail to those mothers who initially agreed to participate. If they consented, a home visit was scheduled. One 1- to 3-h home visit (see Table 1 for specifics by sample) was conducted per family to observe children's secure base behavior. In addition, Colombian and Peruvian dyads were also observed at a 60 - to 75 -min playground visit, and U.S. dyads were observed at two 60- to 75-min playground visits. AQS descriptions from both contexts were composited. 
Table 1

Demographic Characteristics and Procedures

\begin{tabular}{|c|c|c|c|c|c|c|c|c|c|}
\hline & Canada & Colombia & France & Italy & Japan & Peru & Portugal & Taiwan & U.S. \\
\hline \multicolumn{10}{|l|}{ Children } \\
\hline$N$ & 63 & 83 & 30 & 39 & 45 & 30 & 112 & 68 & 77 \\
\hline \multicolumn{10}{|l|}{ Gender: } \\
\hline Boy/girl & $38 / 25$ & $39 / 44$ & $15 / 15$ & $18 / 21$ & $23 / 22$ & $17 / 13$ & $54 / 58$ & $37 / 31$ & $37 / 40$ \\
\hline $\begin{array}{l}\text { Age in } \\
\text { months } \\
\text { (range) }\end{array}$ & $24.8(10-48)$ & $43(39-48)$ & $18.3(17-20)$ & $40(31-55)$ & $14(13-16)$ & $61(49-72)$ & $28.6(18-44)$ & $55(50-59)$ & $44.4(40-50)$ \\
\hline \multicolumn{10}{|l|}{ Mothers } \\
\hline $\begin{array}{l}\text { Age in } \\
\text { years } \\
\text { (range) }\end{array}$ & $26.3(18-45)$ & $31(19-45)$ & $24(20-28)$ & $34.8(20-43)$ & $31.5(21-42)$ & $35(25-45)$ & $34.4(25-48)$ & $34(27-42)$ & $34.2(22-55)$ \\
\hline $\begin{array}{l}N \text { of } \\
\text { children }\end{array}$ & 1.4 & 2 & 1 & 1.8 & 1 & 1.9 & 1.5 & 1.8 & 2 \\
\hline $\begin{array}{l}\text { Education } \\
\text { (years) }\end{array}$ & 10.8 & 14 & 10 & 14 & 14.7 & 12.6 & 15.3 & 14.9 & 16.5 \\
\hline \multicolumn{10}{|l|}{ Experts } \\
\hline$N$ & 8 & 7 & 8 & 10 & 8 & 9 & 15 & 10 & 6 \\
\hline Female/male & $8 / 0$ & $7 / 0$ & $8 / 0$ & $6 / 4$ & $5 / 3$ & $9 / 0$ & $10 / 5$ & $9 / 1$ & $3 / 3$ \\
\hline $\begin{array}{l}\text { Mean ed. } \\
\text { years }\end{array}$ & 19 & 19.5 & 17 & 22.1 & 21.9 & 19.7 & 18 & 22.9 & $\geq 20$ \\
\hline $\begin{array}{l}\text { University } \\
\text { professor }\end{array}$ & 4 & 4 & 0 & 5 & 6 & 3 & 2 & 10 & 6 \\
\hline \multicolumn{10}{|l|}{ Procedures } \\
\hline Region & Montreal & Bogota & Paris & $\begin{array}{l}\text { Bari \& } \\
\text { Chieti }\end{array}$ & Sapporo & Lima & Lisbon & Taipei & Midwest \\
\hline Context & Home & $\begin{array}{c}\text { Home \& } \\
\text { park }\end{array}$ & Home & Home & Home & $\begin{array}{l}\text { Home \& } \\
\text { park }\end{array}$ & Home & Home & $\begin{array}{l}\text { Home \& } \\
\text { park }\end{array}$ \\
\hline Observation & 2 & $2.5-3$ & 2 & 2 & $1.5-2$ & 1 & 2 & 3 & $2.5-3$ \\
\hline Length (hrs) & & $1-1.25$ & & & & 1 & & & $2-2.5$ \\
\hline
\end{tabular}

The Attachment Q-set (Waters, 1995) was used to describe children's behavior. Home visits were unstructured for the most part, such that mothers were told to go about their activities as they would normally. Observers were allowed to interact naturally with both mother and child during the visits. The home visits also included some more structured activities. Thus, in different samples mothers were asked to have a snack, read a book, construct a puzzle, and/or play with their child with their usual toys. For the Colombian, Peruvian, Taiwanese, and U.S. samples, mothers and children were asked to complete other brief research tasks. Also, Japanese mothers were interviewed about childrearing during the visit.

Observers were trained in the use of the AQS. Training consisted of first reading and discussing the meaning of the items. This was followed by 3-6 practice observations and descriptions of child behavior during child-mother interactions at home (or from videotapes of family visits) with the AQS. Trainees' descriptions were compared with those of an expert. An observer was considered trained when he or she obtained an interobserver reliability (with expert) of at least .70 in three practice observations. In the samples from France, Italy, Japan, and Portugal, two observers conducted the visits. In Colombia, 124 of 166, in Peru, 19 of 60, in Taiwan, 20 of 68, and in the United States, 101 of 231 visits were conducted by two observers. For the Canadian sample, the home visit was conducted by one observer. In the samples from Colombia, Peru, and the United States where there were additional visits (home and playground), at least one of the two observers for the playground visit had not gone on the home visit. After each visit, observers independently described the child's behavior with the AQS. Disagreements (i.e., items placed farther than three piles apart) were resolved through discussion. 
Experts were asked to describe the hypothetical "most secure" child with the AQS 90 items. If necessary, they were also instructed as to how to use q-methodology.

\section{Assessment}

Secure base behavior. Children's behavior during interactions with their mothers was described with the AQS (Waters, 1995). This instrument assesses the organization of attachment behavior in naturalistic settings. The AQS was created for use with infants and preschool children (Cicchetti, Cummings, Greenberg, \& Marvin, 1990; Waters \& Deane, 1985) and its validity has been documented elsewhere (e.g., van IJzendoorn et al., 2004; Vaughn \& Waters, 1990). The validity of the AQS when used in cultures other than those representing Western industrialized countries has been supported in different studies conducted in Colombia, Japan, and Israel (e.g., Posada et al., 1995, 1999, 2002, 2004; van IJzendoorn et al., 2004; Vereijken et al., 1997). The Q-set was first translated into the language of the participating countries by members of the different research teams and then translated back into English by a different researcher. The English versions were compared and items were revised if their meaning was inaccurate.

Mean interobserver reliability indices (calculated from the agreement between q-descriptions from independent observers) ranged from .71 to .84 . Mean reliability indices by country were: Colombia, .84 (.64-.95); France, .74 (.62-.86); Italy, .71 (.63-.80); Japan, .74 (.70-.90); Peru, .79 (.64-.94); Portugal, .72 (.60-.89); Taiwan, .84 (.79-.90); and United States, .76 (.60-.89). The descriptions provided by observers were averaged into a composite q-description. Security scores were calculated for each child's composite description. A security score expresses the degree of correspondence between a child's description and the AQS criterion sort, which describes the hypothetically secure child (Waters, 1995). The Pearson correlation index between those two descriptions is the security score. Both composite q-descriptions and security scores were used for analyses.

\section{Results}

Descriptive statistics for security scores by country are presented in Table 2. Our first question asked whether descriptions of child behavior, during child-mother exchanges in naturalistic settings,
Table 2

Means, Standard Deviations, and Range of Security Scores by Country

\begin{tabular}{lrrrr}
\hline & \multicolumn{3}{c}{ Security } & \\
\cline { 2 - 4 } & $N$ & $M$ & $S D$ & Range \\
\hline Canada & 63 & .31 & .23 & $-.26-.73$ \\
Colombia & 83 & .32 & .22 & $-.25-.67$ \\
France & 30 & .34 & .22 & $-.23-.68$ \\
Italy & 39 & .39 & .22 & $-.26-.67$ \\
Japan & 45 & .19 & .27 & $-.44-.55$ \\
Peru & 30 & .30 & .27 & $-.37-.66$ \\
Portugal & 112 & .45 & .23 & $-.17-.82$ \\
Taiwan & 68 & .32 & .15 & $-.03-.59$ \\
United States & 77 & .44 & .18 & $-.19-.77$ \\
\hline
\end{tabular}

reflect children's use of mother as a secure base. It was expected that most security scores were positive (i.e., indicating the presence of the secure base phenomenon). We plotted children's security scores for each sample and the resulting graph (see Figure 1) shows that the scores fell almost entirely within the positive range in each of the nine samples studied. The majority of children observed had positive security scores, indicating that their behavior tends to resemble that of a child using her or his mother as a secure base. Mean security scores in all countries were positive, ranging from .19 to .45.

Our second question was concerned with whether patterns of children's secure base use were similar across countries or whether similarities emerged within specific countries. Correlations between all pairs of AQS descriptions, both within and across samples, were computed. Viewing each q-sort as a 90-item profile of secure base behavior organization, each of those correlations provides an index of similarity between profiles. The correlation indices were subsequently transformed to Fisher's $z$, averaged within and between countries, and then converted back to Pearson correlations. The similarity of secure base behavior profiles observed across cultures $(M=.25$, range $=.12-.36)$ is not markedly different from that obtained within countries $(M=.33$, range $=.16-.45$; see Table 3$)$. In no case did observers' descriptions emerge as highly similar within one country, yet very unlike those in other countries. In six samples, the mean for within-country correlations was either smaller than or equal to any of the between country mean correlations for those samples. The three exceptions were Peru, Taiwan, and United States where the within-country correlation means were slightly larger than any of their between-country correlation means. 


\section{Canada}

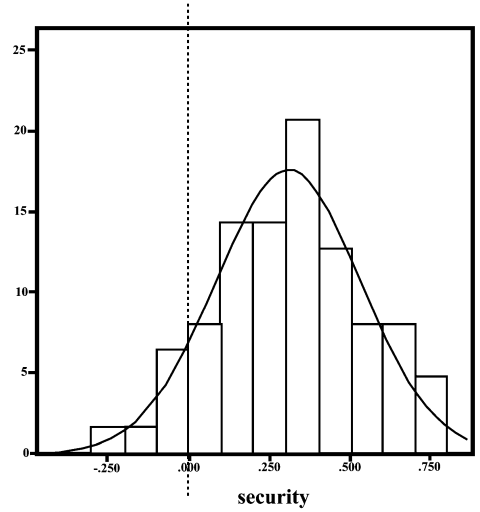

France

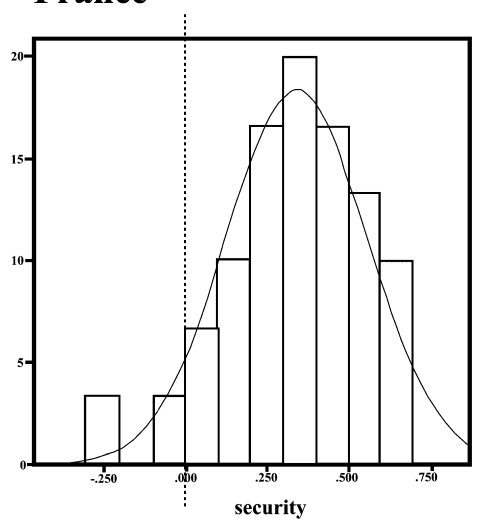

Japan

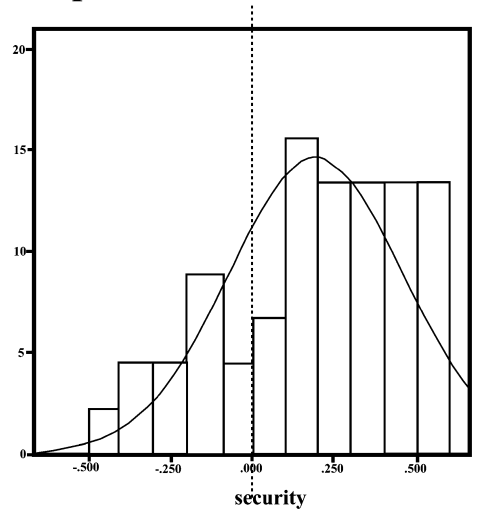

\section{Columbia}

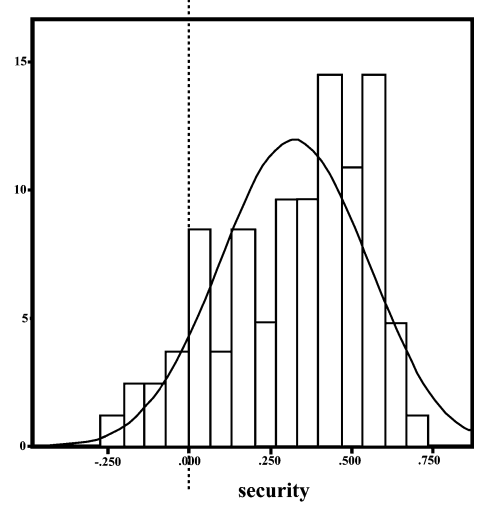

Italy

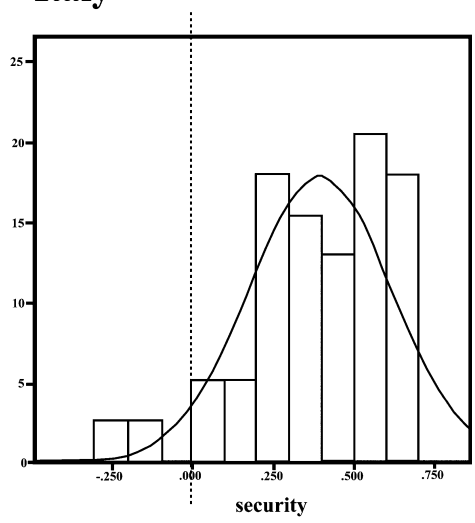

Peru

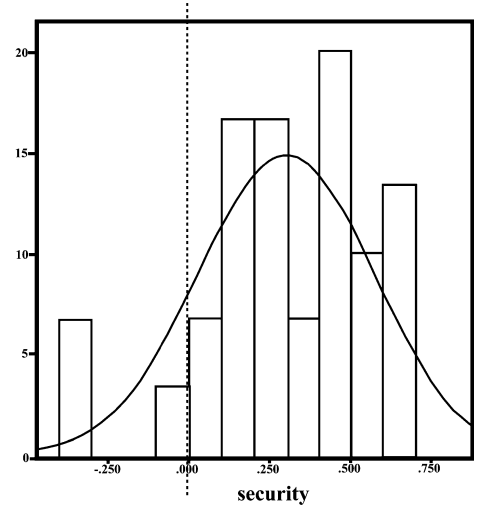

Figure 1. Distribution of security scores (percentage) by country. The dashed lines indicate the potential midpoint of the scale if the full range of scores were obtained.

The degree of similarity among behavioral descriptions found certainly allows for the presence of between country differences. In an exploratory fashion, we studied whether the samples differed in specific behavioral domains of the secure base phenomenon as assessed by the AQS. Four scales were derived from the AQS: Smooth Interactions With Mother, Proximity to Mother, Physical Contact With Mother, and Interactions With Other Adults, all representing a specific yet interrelated aspect of secure base use (Posada, Waters, Crowell, \& Lay, 1995). These scales refer to behavior central to the secure base phenomenon.

One-way analysis of variance tests were conducted and significant differences were found on all four scales. Bonferroni pairwise comparisons were then used to explore the sources of those differences (Table 4). Overall, 31 of 144 pairwise 
Portugal

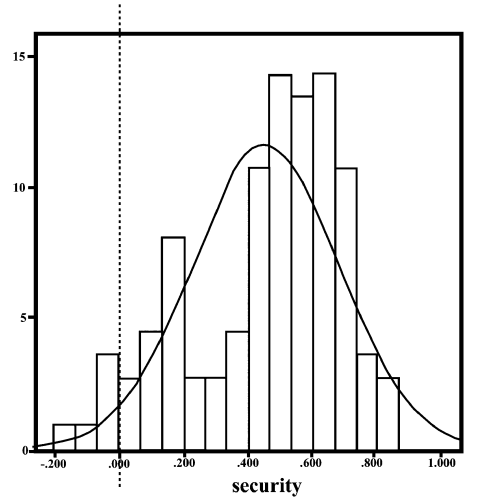

United States

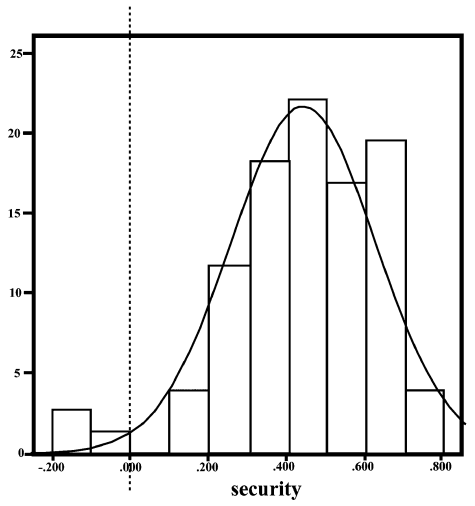

Taiwan

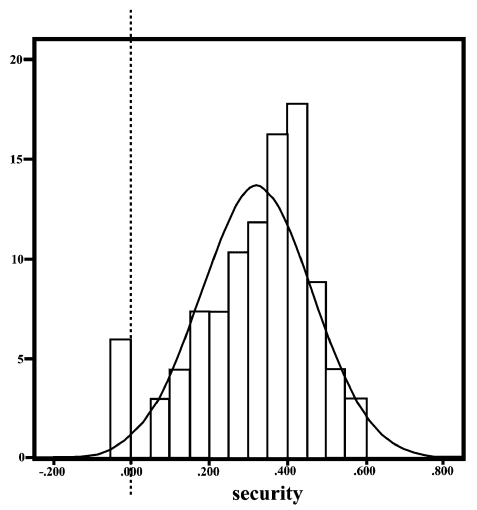

Figure 1. Continued

Table 3

Mean Correlations Among Q-Sort Descriptions Both Within and Across Countries

\begin{tabular}{|c|c|c|c|c|c|c|c|c|c|}
\hline & Canada & Colombia & France & Italy & Japan & Peru & Portugal & Taiwan & United States \\
\hline Canada & .21 & & & & & & & & \\
\hline Colombia & .23 & .38 & & & & & & & \\
\hline France & .21 & .28 & .29 & & & & & & \\
\hline Italy & .21 & .24 & .17 & .32 & & & & & \\
\hline Japan & .12 & .15 & .25 & .17 & .16 & & & & \\
\hline Peru & .21 & .36 & .25 & .24 & .13 & .42 & & & \\
\hline Portugal & .22 & .29 & .27 & .27 & .17 & .27 & .35 & & \\
\hline Taiwan & .20 & .28 & .25 & .27 & .14 & .29 & .26 & .35 & \\
\hline United States & .26 & .36 & .32 & .31 & .19 & .36 & .34 & .31 & .45 \\
\hline
\end{tabular}

Note. The values in boldface are within-country correlations.

comparisons yielded significant differences. No consistent discernible pattern of differences in the scales among countries was detected. On the Smooth Interactions With Mother scale, children from Japan were found to have lower scores than those of children from any other country except France. On the Proximity to Mother scale, children from Colombia, Peru, and Taiwan had significantly lower scores than scores of children from Italy,
Japan, and Portugal. In addition, children from Colombia had significantly lower scores than those of children from Canada. On the Physical Contact With Mother scale, children from Portugal had significantly higher scores than those of children from all other countries except France and Italy. Furthermore, children from Italy had significantly higher scores than those of children from Colombia, Peru, Taiwan, and the United States. Finally, on the 
Table 4

Comparison Among Countries on the Attachment Q-Set Scales

\begin{tabular}{|c|c|c|c|c|c|c|c|c|c|c|}
\hline & Canada & Colombia & France & Italy & Japan & Peru & Portugal & Taiwan & U.S. & $F$ \\
\hline \multicolumn{11}{|c|}{ Smooth Interactions With Mother } \\
\hline$M$ & $6.17 \mathrm{a}$ & $6.31_{\mathrm{a}}$ & $6.03_{\mathrm{ab}}$ & $6.36_{a}$ & $5.28_{\mathrm{b}}$ & $6.33_{\mathrm{a}}$ & $6.26_{a}$ & $6.35_{a}$ & $6.39 \mathrm{a}$ & \multirow[t]{3}{*}{$4.39 * * *$} \\
\hline$S D$ & 1.23 & 1.05 & 1.26 & 1.15 & 1.28 & 1.18 & 1.30 & .98 & .92 & \\
\hline Range & $2.06-8.47$ & $3.28-7.82$ & 2.79-7.91 & $3.82-8.24$ & $2.76-7.74$ & $3.00-7.98$ & $3.35-8.32$ & $3.82-8.12$ & $3.45-7.61$ & \\
\hline \multicolumn{11}{|c|}{ Proximity to Mother } \\
\hline$M$ & $5.44_{\mathrm{ab}}$ & $4.72_{c}$ & $5.22_{\mathrm{abc}}$ & $5.95 \mathrm{a}$ & $5.73_{a}$ & $4.73_{\mathrm{bc}}$ & $5.74_{a}$ & $5.14_{\mathrm{bc}}$ & $5.31_{\mathrm{abc}}$ & \multirow[t]{3}{*}{$7.40 * * *$} \\
\hline$S D$ & 1.34 & 1.17 & 1.19 & 1.19 & 1.52 & 1.23 & 1.24 & 1.12 & .91 & \\
\hline Range & $2.38-8.23$ & $2.02-7.35$ & $2.62-7.62$ & $2.31-7.77$ & $2.15-7.69$ & $2.23-6.56$ & $2.73-8.23$ & $2.77-7.31$ & $3.38-6.94$ & \\
\hline \multicolumn{11}{|c|}{ Physical Contact With Mother } \\
\hline$M$ & $5.78_{\mathrm{bc}}$ & $5.30_{\mathrm{c}}$ & $5.99_{\mathrm{abc}}$ & $6.41_{\mathrm{ab}}$ & $5.81_{\mathrm{bc}}$ & $5.33_{\mathrm{c}}$ & $6.39 \mathrm{a}$ & $5.74_{c}$ & $5.69_{\mathrm{c}}$ & \multirow[t]{3}{*}{$10.39 * * *$} \\
\hline$S D$ & 1.24 & .79 & 1.10 & 1.12 & 1.17 & .68 & .99 & 1.06 & .76 & \\
\hline Range & $3.14-8.00$ & $3.71-7.00$ & $3.43-8.00$ & $4.14-7.86$ & $3.43-7.50$ & $3.57-6.67$ & $3.93-8.00$ & $3.29-7.71$ & $4.18-7.05$ & \\
\hline \multicolumn{11}{|c|}{ Interactions With Other Adults } \\
\hline$M$ & $5.50_{\mathrm{ab}}$ & $5.65_{\mathrm{ab}}$ & $6.13_{\mathrm{a}}$ & $5.86_{\mathrm{ab}}$ & $5.03_{\mathrm{b}}$ & $5.63_{\mathrm{ab}}$ & $5.82_{\mathrm{a}}$ & $6.20_{a}$ & $5.66_{\mathrm{ab}}$ & \multirow[t]{3}{*}{$3.42 * * *$} \\
\hline$S D$ & 1.24 & 1.42 & 1.39 & 1.22 & 1.68 & 1.27 & 1.37 & 1.11 & 1.19 & \\
\hline Range & $1.38-7.92$ & $2.44-7.73$ & $3.27-8.00$ & $3.00-7.77$ & $2.35-7.85$ & $2.46-7.31$ & $1.92-8.15$ & $2.85-8.00$ & $2.02-7.62$ & \\
\hline
\end{tabular}

Note. Means in the same row that do not share subscripts differ at $p<.05$.

$* * * p<.001$.

Interactions With Other Adults scale, children from Japan had significantly lower scores than those of children from France, Portugal, and Taiwan.

Finally, we examined whether child professionals from different cultures described optimal secure base organization in similar ways. Expert composites by country were created by averaging their qdescriptions of the hypothetically, most securely attached child. Subsequently, those composite descriptions were correlated. The correlations among experts from different samples were very high and ranged from .82 to .97 , suggesting that notions of optimality, as far as the secure base phenomenon is concerned, are similar across countries. Range of correlations between composites in one country and those from other countries was as follows: Canadian experts, .84-.96; Colombian, .82-.91; French, .83-.92; Italian, .85-.91; Japanese, .84-.91; Peruvian, .82-.89; Portuguese, .88-.97; Taiwanese, .82-.91; and United States, .88 to .97 .

\section{Discussion}

The ability to use a caregiver as a secure base is a behavioral manifestation of the emotional bond that the child has co-constructed with her or his mother. This emotional bond, product of child-mother interactions, is hypothesized to be evident in all children exposed to ordinary care. We collected information on toddlers and preschoolers' behavior in naturalis- tic contexts to test Bowlby's universality hypothesis. Children from all countries exhibited the secure base phenomenon as assessed by the AQS during exchanges with their mothers. In all samples, the distribution of security scores was negatively skewed. Descriptions of their behavior indicated that children use their mothers as a base from which to explore their surroundings and as a haven of safety. These findings support the universality hypothesis of attachment relationships (van IJzendoorn \& Sagi, 2008). Furthermore, the data support the idea that the secure base phenomenon is apparent in children beyond the first 2 years, specifically into the preschool years, as information obtained in several countries sampled here (i.e., Colombia, Italy, Peru, Taiwan, and United States) was from children whose ages ranged between 3 and 5 years.

We also investigated whether children's organization of secure base behavior was similar across countries or whether it exhibited more similarity within countries. All in all, comparisons of the behavioral profile obtained for each child with that of other children from the same country and that of other children from different countries showed that the organization of secure base behavior is not more similar within countries than across countries. These results are in line with evidence reported elsewhere (Posada et al., 1995; van IJzendoorn \& Kroonenberg, 1988) and support the notion that the structure of secure base behavior is similar across countries during the early years of life. Furthermore, consistent 
with evidence supporting the universality hypothesis, most $(78 \%)$ sample comparisons across four specific behavioral domains central to the secure base phenomenon, as assessed by the AQS, indicated that children' scores were similar across countries. The remaining pairwise comparisons signaled sample differences. The differences, however, did not evince a clear pattern by country.

The last question we addressed concerned experts' descriptions of optimal secure base behavior. Secure base behavior indicative of a smoothly functioning child-mother relationship is seen alike by experts from different countries. This confirms previous results (Posada et al., 1995) and also extends them to experts from countries not previously considered (i.e., Canada, Italy, Peru, Portugal, and Taiwan). Notions of optimality in behavior covered by the AQS cannot be simply dismissed as culturally biased. Such high degrees of correspondence in their descriptions may be due to foundational knowledge acquired during professional training, and/or to knowledge on child development and child-mother relationships obtained through their experience of working with children and their families.

Overall, the findings presented cannot be construed as due to a methodological artifact. The AQS does not assume the existence of the secure base phenomenon and does not constrain the description of child behavior to conform to the secure base game. It allows for the possibility of describing a behavioral organization that is inconsistent with and/or unrelated to the secure base phenomenon. Indeed, the behavior of very few children was described as either unrelated or negatively related to secure base behavior. Furthermore, using a different criterion sort, that of the dependent child (Waters \& Deane, 1985), to calculate children's dependency scores in the same manner we obtained our security scores, yielded a distribution of scores that ranged from -.62 to $.71, M=-.11$ (means for dependency scores by country ranged from -.21 to .06). This indicates that the distributions obtained were not necessarily skewed in one direction. In brief, the AQS does not presume the existence of the secure base phenomenon. The tendency for the positive security scores found in the data cannot be dismissed as a methodological by-product.

It is necessary to note some limitations of the study and future directions. Specifically, findings based on single samples do not necessarily reflect cross-national tendencies. Importantly, however, the data on samples from Colombia, Japan, and the United States begin to address the issue of sample specificity as they replicate findings reported elsewhere (Posada et al., 1995). Nonetheless, we need confirmatory evidence for the results presented. Also, across-country comparisons would be facilitated if length and contexts of observation, and sample characteristics, were similar. This dissimilarity, however, speaks to the strength of the phenomenon in question, that is, the universality hypothesis. Furthermore, it is important to explore why children's behavioral configurations were modestly or moderately related to each other within and across countries. Does this finding reflect methodological (e.g., measurement) issues, or are there individual or sample-specific factors that may account for it? We, too, need information on secure base behavior in different ecologies within countries, as the construction of secure base relationships is likely to be sensitive to the living circumstances of the dyad (Egeland \& Farber, 1984; Posada et al., 1999; van IJzendoorn \& Sagi, 2008; Vaughn, Egeland, Sroufe, \& Waters, 1979). Finally, we need observations of maternal secure base support in those ecologies.

In conclusion, trained observers' descriptions of young children (1-6 years) in nine different countries representing different cultures indicate that cross-culturally, children use their mothers as a secure base. They offer supporting data in a new set of samples (i.e., Canada, France, Italy, Peru, Portugal, and Taiwan) and replicating evidence for previously studied countries (i.e., Colombia, Japan, and the United States). They also extend previous results on infants to preschoolers. Findings provide confirmatory evidence for the universality hypothesis concerning attachment relationships.

\section{References}

Ainsworth, M. D. S. (1967). Infancy in Uganda. Baltimore: Johns Hopkins University Press.

Block, J. (1978). The Q-sort method in personality assessment and psychiatric research. Palo Alto, CA: Consulting Psychologists Press.

Bowlby, J. (1982). Attachment and loss: Vol. 1. Attachment. New York: Basic Books. (Original work published 1969)

Bowlby, J. (1988). A secure base: Parent-child attachment and healthy human development. New York: Basic Books.

Bretherton, I. (1995). A communication perspective on attachment relationships and internal working models. In E. Waters, B. Vaughn, G. Posada, \& K. Kondo-Ikemura (Eds.), Caregiving, cultural and cognitive perspectives on secure-base behavior and working models: New growing points of attachment theory and research. Monographs of the Society for Research in Child Development, 60(2-3, 
Serial No. 209), 310-329. doi:10.1111/j.1540-5834.1995. tb00220.x

Cicchetti, D., Cummings, E. M., Greenberg, M. T., \& Marvin, R. S. (1990). An organizational perspective on attachment beyond infancy. In M. T. Greenberg, D. Cicchetti, \& E. M. Cummings (Eds.), Attachment in the preschool years (pp. 3-49). Chicago: University of Chicago Press.

De Wolff, M. S., \& van IJzendoorn, M. H. (1997). Sensitivity and attachment: A meta-analysis on parental antecedents of infant attachment. Child Development, 68, 571591. doi:10.1111/j.1467-8624.1997.tb04218.x

Egeland, B., \& Farber, E. A. (1984). Infant-mother attachment: Factors related to its development and changes over time. Child Development, 55, 753-771. doi:10.1111/1467-8624.ep12423582

Goldsmith, H. H., \& Alansky, J. A. (1987). Maternal and infant temperamental predictors of attachment: A metaanalytic review. Journal of Consulting and Clinical Psychology, 55, 805-816. doi:10.1037/0022-006X.55.6.805

Heinicke, C. M. (1995). Expanding the study of the formation of the child's relationships. In E. Waters, B. Vaughn, G. Posada, \& K. Kondo-Ikemura (Eds.), Caregiving, cultural and cognitive perspectives on secure-base behavior and working models: New growing points of attachment theory and research. Monographs of the Society for Research in Child Development, 60(2-3, Serial No. 244), 300-309. doi:10.1111/j.1540-5834.1995.tb00219.x

Oyserman, D., Coon, H., \& Kemmelmeier, M. (2002). Rethinking individualism and collectivism: Evaluation of theoretical assumptions and meta-analyses. Psychological Bulletin, 138, 3-72. doi:10.1037/0033-2909.128.1.3

Posada, G., Carbonell, O. A., Alzate, G., \& Plata, S. J. (2004). Through Colombian lenses: Ethnographic and conventional analyses of maternal care and their associations with secure base behavior. Developmental Psychology, 40, 508-518. doi:10.1037/0012-1649.40.4.508

Posada, G., Gao, Y., Fang, W., Posada, R., Tascon, M., Schoelmerich, A., et al. (1995). The secure-base phenomenon across cultures: Children's behavior, mothers' preferences, and experts' concepts. In E. Waters, B. Vaughn, G. Posada, \& K. Kondo-Ikemura (Eds.), Caregiving, cultural and cognitive perspectives on secure-base behavior and working models: New growing points of attachment theory and research. Monographs of the Society for Research in Child Development, 60(2-3, Serial No. 244), 27-48. doi:10.1111/j.1540-5834.1995.tb00202.x

Posada, G., Jacobs, A., Carbonell, O. A., Alzate, G., Bustamante, M. R., \& Arenas, A. (1999). Maternal care and attachment security in ordinary and emergency contexts. Developmental Psychology, 35, 1379-1388. doi:10.1037/0012-1649.35.6.1379

Posada, G., Jacobs, A., Richmond, M. K., Carbonell, O. A., Alzate, G., Bustamante, M. R., et al. (2002). Maternal caregiving and infant security in two cultures. Developmental Psychology, 38, 67-78. doi:10.1037/00121649.38.1.67

Posada, G., Waters, E., Crowell, J. A., \& Lay, K. L. (1995). Is it easier to use a secure mother as a secure base?
Attachment Q-sort correlates of the adult attachment interview. In E. Waters, B. Vaughn, G. Posada, \& K. Kondo-Ikemura (Eds.), Caregiving, cultural and cognitive perspectives on secure-base behavior and working models: New growing points of attachment theory and research. Monographs of the Society for Research in Child Development, 60(2-3, Serial No. 244), 133-145. doi:10.1111/ j.1540-5834.1995.tb00208.x

van IJzendoorn, M. H., \& Kroonenberg, P. M. (1988). Cross-cultural patterns of attachment: A meta-analysis of a strange situation. Child Development, 59, 147-156. doi:10.1111/1467-8624.ep10514129

van IJzendoorn, M. H., \& Sagi, A. (2008). Cross-cultural patterns of attachment: Universal and contextual dimensions. In J. Cassidy \& P. Shaver (Eds.), Handbook of attachment: Theory, research and clinical applications (pp. 880-905). New York: Guilford.

van IJzendoorn, M. H., Vereijken, C., Bakermans-Kranenburg, M. J., \& Riksen-Walraven, J. M. (2004). Assessing attachment security with the attachment Q-sort: Metaanalytic evidence for the validity of the observer AQS. Child Development, 75, 1188-1213. doi:10.1111/j.14678624.2004.00733.x

Vaughn, B. E., Egeland, B. R., Sroufe, L. A., \& Waters, E. (1979). Individual differences in infant-mother attachment at twelve and eighteen months: Stability and change in families under stress. Child Development, 50, 971-975. doi:10.1111/1467-8624.ep7251685

Vaughn, B. E., \& Waters, E. (1990). Attachment behavior at home and in the laboratory: Q-sort observations and Strange Situation classifications of one-year-olds. Child Development, 61, 1965-1973. doi:10.1111/j.1467-8624. 1990.tb03578.x

Vereijken, C., Riksen-Walraven, J., \& Kondo-Ikemura, K. (1997). Maternal sensitivity and infant attachment security in Japan: A longitudinal study. International Journal of Behavioral Development, 21, 35-49. doi:10.1080/ 016502597384974

Waters, E. (1995). Attachment Q-set items. In E. Waters, B. Vaughn, G. Posada, \& K. Kondo-Ikemura (Eds.), Caregiving, cultural and cognitive perspectives on securebase behavior and working models: New growing points of attachment theory and research. Monographs of the Society for Research in Child Development, 60(2-3, Serial No. 209), 255-265. doi:10.1111/j.1540-5834.1995.tb00214.x

Waters, E., \& Deane, K. E. (1985). Defining and assessing individual differences in attachment relationships: Q-methodology and the organization of behavior in infancy and early childhood. In I. Bretherton \& E. Waters (Eds.), Growing points in attachment theory and research. Monographs of the Society for Research in Child Development, 50(1-2, Serial No. 209), 41-65. doi: $10.2307 / 3333826$

Wu, P., \& Zou, H. (1995). The association between attachment quality and peer relationships of preschool children. Acta Psychologica Sinica, 27, 434-441. doi:CNKI: SUN:XLXB.0.1995-04-014 